\title{
Airway iron and iron-regulatory cytokines in cystic fibrosis
}

\author{
D.W. Reid*,\#, Q.T. Lam", H. Schneider", E.H. Walters"
}

Airway iron and iron-regulatory cytokines in cystic fibrosis. D.W. Reid, Q.T. Lam, H. Schneider, E. H. Walters. C) ERS Journals Ltd 2004.

ABSTRACT: Iron availability is critical to Pseudomonas aeruginosa. The current authors determined sputum iron, ferritin, microalbumin levels and total cell counts (TCC) in 19 adult patients with cystic fibrosis (CF) during an acute exacerbation and repeated analyses following a median of 12 days antibiotic treatment. The current authors also determined sputum interleukin (IL)-1 $\beta$ and tumour necrosis factor (TNF)$\alpha$ levels because of their putative role in intracellular iron homeostasis. Additional data were obtained from 17 stable $C F$ patients, eight patients with stable chronic obstructive pulmonary disease (COPD) and six normal subjects.

Overall, sputum iron, ferritin, microalbumin, IL-1 $\beta$ and TNF- $\alpha$ concentrations and TCCs were significantly elevated in the CF patients compared to those with COPD and normal controls. Sputum ferritin levels were significantly elevated in acute versus stable CF patients and there was a trend for sputum TCC to be higher, but all other inflammatory indices were similar. In the $C F$ patients, sputum iron was positively and strongly related to IL-1ß, TNF- $\alpha$, ferritin and microalbumin levels, but negatively related to forced expiratory volume in one second \% predicted. In those acute patients who clinically improved with antibiotics $(n=14)$, there were significant decreases in sputum TCC, iron, ferritin and IL-1 $\beta$ content, but not TNF- $\alpha$ or albumin levels. However, changes in sputum TNF- $\alpha$ in acute patients were still closely related to changes in iron, ferritin and albumin content, and changes in IL-1ß were related to changes in sputum ferritin content.

Iron and iron-regulatory cytokines may play a role in cystic fibrosis lung disease and the increased iron content may even facilitate Pseudomonas aeruginosa infection. Eur Respir J 2004; 24: 286-291.

\begin{abstract}
*Adult Cystic Fibrosis Centre, and $D$ Dept of Pathology, Alfred Hospital and Monash University Medical School, Melbourne, and ${ }^{\#}$ Discipline of Medicine, University of Tasmania, Tasmania, Australia.
\end{abstract}

Correspondence: D. Reid

Discipline of Medicine

University of Tasmania

Collins Street

Hobart

Tasmania

Australia

Fax: 61392763434

E-mail: David.Reid@monash.edu.au

Keywords: Cystic fibrosis

iron

Pseudomonas aeruginosa

Received: September 152003

Accepted after revision: March 32004

Support for the iron and cytokine assays was provided altruistically by Novartis Pharmaceuticals.
Cystic fibrosis $(\mathrm{CF})$ is the most common life-limiting genetic disorder in people of European, especially Anglo-Celtic, descent. The respiratory complications manifest as chronic sinopulmonary infection and are primarily responsible for the reduced longevity of $\mathrm{CF}$ patients [1]. Patients develop airway infection and inflammation in childhood, and colonisation by the Gram-negative organism Pseudomonas aeruginosa heralds a cycle of chronic sepsis and episodes of acute exacerbation that ultimately lead to airway and parenchymal destruction and respiratory failure [2].

The airway epithelium responds to $P$. aeruginosa infection by generating pro-inflammatory cytokines, such as interleukin (IL)-8, IL-1 $\beta$ and tumour necrosis factor (TNF)- $\alpha$, which regulate the host immune response [3]. Additionally, IL-1 $\beta$ and TNF- $\alpha$ influence intracellular iron homeostasis, although this role has not been previously examined in vivo in CF [4]. This is surprising as $P$. aeruginosa has an absolute requirement for iron for replication and any increase in accessible iron within the $\mathrm{CF}$ airway may have profound implications for $P$. aeruginosa virulence. This may be particularly so in a host who, paradoxically, may have an impaired systemic immune system because of coexisting systemic iron deficiency $[5,6]$.

In this study, the current authors have measured the content of iron and ferritin within sputum samples of $19 \mathrm{CF}$ patients experiencing an acute infective exacerbation and in 17 stable patients, to test the hypothesis that iron may be relevant to airway inflammation and potentially to the pathogenesis of $P$. aeruginosa infection in this disease. The sputum concentration of microalbumin was also determined to assess whether vascular leakage may be contributing to the presence of iron within the airway. Furthermore, the sputum levels of the cytokines IL- $1 \beta$ and TNF- $\alpha$ were measured to assess their association with the inflammatory process. Finally, the response of these sputum solutes during an acute infective exacerbation to antimicrobial therapy was determined. Comparative baseline data was obtained from six healthy nonsmoking controls and eight subjects with mild stable smoking-related chronic obstructive pulmonary disease (COPD).

\section{Methods}

\section{Subjects}

The current authors studied spontaneously expectorated sputum samples from 19 adult subjects with $\mathrm{CF}$ who were admitted with a history of an acute infective exacerbation, i.e. increase in cough, sputum volume and breathlessness, usually with fevers and loss of weight. Additionally, iron-related inflammatory mediators were assessed in 17 stable CF patients, i.e. no exacerbation within the preceding 4 weeks. Subjects with a history of haemoptysis within the preceding month were excluded. Sputum was obtained within $72 \mathrm{~h}$ of an acute admission or during a routine clinic visit and culture results were recorded. In the acute patients, the current authors 
repeated sputum analyses following a minimum period of 7 days (median 12 days, range 7-61 days) of i.v. antibiotic treatment. Sputum analysis in these subjects was usually repeated at the end of the admission when a beneficial response had been made, or at a time point ( $>5$ days) when a change in antibiotic therapy was being considered because of a poor clinical response. Two patients required prolonged antibiotic treatment for severe airway sepsis, characterised by large volumes of purulent sputum and systemic upset. The patient's clinical response at the time of the second sputum sample was arbitrarily defined as either "good" or "poor," based upon the clinician's overall impression of the patient's progress, i.e. reduction in fever, reduced purulence and volume of sputum, and the patient's general sense of well-being.

The current authors induced sputum using hypertonic saline $(4.5 \%)$ in eight subjects with stable COPD and six normal controls. All sputum samples were processed according to the selected plug method described by PIZZICHINI et al. [7]. The Institutional Ethics Committee approved the study and patients gave informed consent to participate.

\section{Sputum processing}

The sputum samples were refrigerated $\left(4^{\circ} \mathrm{C}\right)$ and processed within $2 \mathrm{~h}$ of expectoration. Sputum plugs free of saliva were selected from the raw sample using dissecting forceps to avoid salivary cellular or solute contamination. The weight of sputum was measured and a volume of $0.1 \%$ dithiothreitol (Sputalysin; Calbiochem Ltd, La Jolla, CA, USA) equivalent to the weight of sputum was added. The sample was thoroughly mixed prior to placing in a water bath at $38^{\circ} \mathrm{C}$ for $30 \mathrm{~min}$ to lyse the mucus. The sample was removed at 10 -min intervals for further mixing and, when adequately homogenised, it was made up to $5 \mathrm{~mL}$ with phosphate buffered saline and centrifuged at $1,500 \mathrm{rpm}$ for $15 \mathrm{~min}$. The supernatant was decanted off and stored in $1-\mathrm{mL}$ aliquots (minimum of five) in an $-80^{\circ} \mathrm{C}$ freezer for later analysis. Total cell counts (TCC) were performed on $20 \mu \mathrm{L}$ of resuspended cell pellet in a Neuhauer counting chamber (Wertheim, Germany).

\section{Total iron, ferritin and albumin assays}

Total iron content of cell-free, unconcentrated sputum supernatant was determined using a routine colorimetric assay (Boehringer-Ingelheim/Hitachi 747 analyser; BoehringerIngelheim, Mannaheim, Germany) and expressed as $\mu \mathrm{mol} \cdot \mathrm{L}^{-1}$. Ferritin concentration was determined by microparticle enzyme immunoassay using an Abbott AXSYM analyser (Abbott, Minneapolis, IL, USA) and expressed as $\mu \mathrm{g} \cdot \mathrm{L}^{-1}$. The albumin concentration in sputum was assessed using rate immunonephelometry with a COBAS FARA II autoanalyser (Roche Diagnostics, Basel, Switzerland) and expressed as $\mathrm{mg} \cdot \mathrm{L}^{-1}$.

\section{$I L-1 \beta$ and TNF- $\alpha$ assays}

Both IL-1 $\beta$ and TNF- $\alpha$ were assessed using standard sandwich immunometric assays (Diagnostics Products Corporation, Los Angeles, CA, USA) and their concentrations determined by chemiluminescence. Assays were performed on a Bio-Mediq DPC Immulite (Bio-Mediq DPC Pty, Doncaster, Victoria, Australia). The lower limit of detection for IL- $1 \beta$ was $1.5 \mathrm{pg} \cdot \mathrm{mL}^{-1}$ and for TNF- $\alpha 1.7 \mathrm{pg} \cdot \mathrm{mL}^{-1}$. Analysis of all sputum solute end-points was performed blinded to clinical outcomes.

Reproducibility of the assays was assessed in 31 individual sputum samples and found to be excellent, with intraclass correlation coefficients of $0.96,0.96,0.97,0.97$ and 0.97 for iron, ferritin, albumin, IL-1 $\beta$ and TNF- $\alpha$ respectively [8].

\section{Statistics}

Data are expressed as medians and ranges, assuming a nonnormal distribution unless otherwise stated. Differences between groups were assessed with the Kruskall-Wallis test for nonparametric data. Treatment effects compared to baseline were determined using Wilcoxon's rank test for paired data. To determine relationships between sputum solute concentrations, Spearman's rank correlation was used. A two-tailed $p \leqslant 0.05$ was considered statistically significant.

\section{Results}

In total, 18 of 19 patients with acute $\mathrm{CF}$ had positive sputum cultures for mucoid $P$. aeruginosa (table 1). One patient (subject seven) was known to be chronically colonised by $P$. aeruginosa, but did not have a sputum culture requested on admission. All of the 17 stable patients had long-standing $P$. aeruginosa infection and two were colonised with Burkholderia cepacia (table 2).

Overall, sputum TCC and iron, ferritin, microalbumin, IL$1 \beta$ and TNF- $\alpha$ concentrations in the CF subjects were significantly elevated compared to subjects with COPD and normal controls (table 3 ). Sputum iron and ferritin levels in the $\mathrm{CF}$ patients generally exceeded those found in normal serum (normal range (NR) for iron $13-32 \mu \mathrm{mol} \cdot \mathrm{L}^{-1}$ and NR for ferritin $15-300 \mu \mathrm{g} \cdot \mathrm{L}^{-1}$ ). Interestingly, patients with COPD had significantly higher levels of iron $(\mathrm{p}=0.01)$ and ferritin $(p<0.05)$ in sputum than normal controls, but all other indices were similar. Although iron levels were generally higher in stable CF compared to COPD patients, this was not statistically significant. The presence of pathogens (apart from $P$. aeruginosa), such as methicillin-resistant Staphylococcus aureus and B. cepacia, did not appear to affect levels of ironrelated mediators in the small number of patients assessed.

There were a number of significant relationships between the sputum inflammatory mediators at the time of acute exacerbation and their relative changes with treatment were similarly closely related (tables 4-7). In particular, iron content was positively related to IL- $1 \beta$ and TNF- $\alpha$ concentrations at baseline and changes in iron, ferritin and albumin concentrations with treatment were strongly related to changes in TNF- $\alpha$. There was a similarly strong relationship between changes in ferritin and IL- $1 \beta$ concentrations. In stable CF patients, iron was very strongly related to IL-1 $\beta$, $\mathrm{TNF}-\alpha$, ferritin and albumin levels and there was a weak relationship to sputum TCC that just reached significance. Sputum iron and ferritin levels in stable patients were negatively related to forced expiratory volume in one second $\%$ pred $(\mathrm{r}=-0.5, \mathrm{p}=0.03$ and $\mathrm{r}=-0.5, \mathrm{p}=0.04$, respectively), but none of the other inflammatory indices assessed were related to disease severity.

Overall, following antibiotic treatment, there was a significant reduction in sputum ferritin levels $(p=0.01)$ and trends towards reductions in sputum TCC $(\mathrm{p}=0.2)$ and iron $(\mathrm{p}=0.1), \mathrm{IL}-1 \beta(\mathrm{p}=0.06)$ and TNF- $\alpha$ levels $(\mathrm{p}=0.2)$, but albumin remained essentially unchanged $(\mathrm{p}=0.3)$. However, in those 15 patients who had definitely improved upon independent prospective clinical assessment, there were significant 
Table 1.-Demographics of acute cystic fibrosis patients

\begin{tabular}{|c|c|c|c|c|c|c|}
\hline Subject & Sex & Age yrs & FEV1 $\%$ & FVC \% & Microbiology & Genotype \\
\hline 1 & $\mathrm{~F}$ & 20 & 32 & 49 & PA (mt, mc) & $\Delta \mathrm{F} 508 / \Delta \mathrm{F} 508$ \\
\hline 2 & $\mathrm{~F}$ & 18 & 61 & 83 & PA $(\mathrm{mt}, \mathrm{mc}), \mathrm{SA}$ & NA \\
\hline $\begin{array}{l}3 \\
4\end{array}$ & $M$ & 20 & 34 & 77 & PA (mt, mc) & NA \\
\hline $\begin{array}{l}4 \\
5\end{array}$ & $\mathrm{M}$ & 21 & 31 & 48 & PA (mt, mc), CA & NA \\
\hline 5 & M & 37 & 45 & 74 & PA $(\mathrm{mc})$ & $\Delta \mathrm{F} 508 / \Delta \mathrm{F} 508$ \\
\hline 6 & M & 32 & 28 & 56 & $\mathrm{PA}(\mathrm{mt}, \mathrm{mc})$ & $\Delta \mathrm{F} 508 / \mathrm{NI}$ \\
\hline 7 & M & 19 & 21 & 33 & NI & $\Delta \mathrm{F} 508 / \Delta \mathrm{F} 508$ \\
\hline 8 & $\mathrm{~F}$ & 40 & 36 & 65 & PA (mt, mc) & $\Delta \mathrm{F} 508 / \Delta \mathrm{F} 508$ \\
\hline 9 & M & 29 & 32 & 69 & $\mathrm{PA}(\mathrm{mc}), \mathrm{CA}$ & $\Delta \mathrm{F} 508 / \Delta \mathrm{F} 508$ \\
\hline 10 & M & 27 & 30 & 61 & $\mathrm{PA}(\mathrm{mt}, \mathrm{mc})$ & $\Delta \mathrm{F} 508 / \Delta \mathrm{F} 508$ \\
\hline 11 & M & 23 & 57 & 82 & PA (mc) & NI \\
\hline 12 & M & 26 & 43 & 84 & PA (mc), CA & $\Delta \mathrm{F} 508 / \Delta \mathrm{F} 508$ \\
\hline 13 & M & 29 & 24 & 50 & PA $(\mathrm{mt}, \mathrm{mc}), \mathrm{MRSA}$ & $\Delta \mathrm{F} 508 / \mathrm{G} 551 \mathrm{D}$ \\
\hline 14 & M & 28 & 37 & 50 & PA $(\mathrm{mt}, \mathrm{mc})$, MRSA & $\Delta \mathrm{F} 508 / \mathrm{NI}$ \\
\hline 15 & M & 28 & 62 & 108 & $\mathrm{PA}(\mathrm{mt}, \mathrm{mc}), \mathrm{SA}$ & $\Delta \mathrm{F} 508 / \mathrm{G} 551 \mathrm{D}$ \\
\hline 16 & M & 34 & 29 & 50 & PA $(\mathrm{mc})$ & $\Delta \mathrm{F} 508 / \mathrm{G} 551 \mathrm{D}$ \\
\hline 17 & $\mathrm{~F}$ & 25 & 35 & 48 & PA (mt, mc) & NA \\
\hline 18 & M & 20 & 32 & 54 & $\mathrm{PA}(\mathrm{mt}, \mathrm{mc}), \mathrm{CA}$ & NA \\
\hline 19 & $\mathrm{~F}$ & 21 & 47 & 69 & PA (mt, mc) & NA \\
\hline Median & $5 \mathrm{~F} / 14 \mathrm{M}$ & $26.5(18-40)$ & $33(21-62)$ & $55(33-108)$ & & \\
\hline
\end{tabular}

Data are presented as $\mathrm{n}$ and median (range) unless otherwise stated. FEV1: forced expiratory volume in one second; FVC: forced vital capacity; F: female; M: male; PA: Pseudomonas aeruginosa; mt: matt; mc: mucoid; SA: Staphylococcus aureus; CA: Candida albicans; MRSA: methicillinresistant $S$. aureus; NA: not available; NI: not identifiable.

Table 2.-Demographics of stable cystic fibrosis patients

\begin{tabular}{|c|c|c|c|c|c|c|}
\hline Subject & Sex & Age yrs & FEV1 \% & FVC \% & Microbiology & Genotype \\
\hline 1 & M & 43 & 54 & 92 & PA (mc) & $\Delta \mathrm{F} 508 / \mathrm{N} 1303 \mathrm{~K}$ \\
\hline 2 & M & 19 & 48 & 61 & PA $(\mathrm{mc})$ & $\Delta \mathrm{F} 508 / \Delta \mathrm{F} 508$ \\
\hline $\begin{array}{l}3 \\
4\end{array}$ & $\begin{array}{l}\mathrm{F} \\
\mathrm{F}\end{array}$ & $\begin{array}{l}43 \\
20\end{array}$ & $\begin{array}{l}99 \\
38\end{array}$ & $\begin{array}{l}100 \\
62\end{array}$ & PA (mt), AF, CA, SM, SP & $\Delta \mathrm{F} 508 / \mathrm{NI}$ \\
\hline 5 & M & 17 & 110 & 117 & PA (mt, mc) & NA \\
\hline 6 & M & 34 & 30 & 53 & $\mathrm{PA}(\mathrm{mt}, \mathrm{mc}), \mathrm{AF}$ & $\Delta \mathrm{F} 508 / \mathrm{G} 551 \mathrm{D}$ \\
\hline 7 & $\mathrm{~F}$ & 25 & 81 & 102 & PA (mc), CA, Penicillium sp. & $\Delta \mathrm{F} 508 / \Delta \mathrm{F} 508$ \\
\hline 8 & $\mathrm{~F}$ & 19 & 44 & 62 & PA $(\mathrm{mc})$ & NA \\
\hline 9 & M & 23 & 29 & 41 & PA (mc) & $\Delta \mathrm{F} 508 / \Delta \mathrm{F} 508$ \\
\hline 10 & M & 20 & 76 & 92 & PA (mt, mc), CA & $\Delta \mathrm{F} 508 / \mathrm{V} 520 \mathrm{~F}$ \\
\hline 11 & M & 43 & 44 & 82 & PA $(\mathrm{mc})$ & $\Delta \mathrm{F} 508 / \mathrm{N} 1303 \mathrm{~K}$ \\
\hline 12 & M & 21 & 44 & 73 & $\mathrm{PA}(\mathrm{mt}, \mathrm{mc}), \mathrm{CA}$ & $\Delta \mathrm{F} 508 / \Delta \mathrm{F} 508$ \\
\hline 13 & M & 22 & 50 & 73 & PA (mc), CA & G524X/NI \\
\hline 14 & $\mathrm{~F}$ & 28 & 76 & 79 & PA (mc), BC & $\Delta$ F508/NI \\
\hline 15 & M & 20 & 55 & 66 & PA (mt), SA, BC & $\Delta \mathrm{F} 508 / \mathrm{G} 551 \mathrm{D}$ \\
\hline 16 & M & 21 & 52 & 61 & PA (mt), CA & NA \\
\hline 17 & M & 23 & 72 & 96 & $\mathrm{PA}(\mathrm{mt}, \mathrm{mc})$ & $\Delta \mathrm{F} 508 / \Delta \mathrm{F} 508$ \\
\hline Median & $5 \mathrm{~F} / 12 \mathrm{M}$ & $22(17-43)$ & $52(29-110)$ & $73(41-117)$ & & \\
\hline
\end{tabular}

Data are presented as $\mathrm{n}$ and median (range) unless otherwise stated. Forced expiratory volume in one second (FEV1) and forced vital capacity (FVC) in the acute patients represent baseline lung function when clinically stable. M: male; F: female; PA: Pseudomonas aeruginosa; mc: mucoid; mt: matt; AF: Aspergillus fumigatus; CA: Candida albicans; SM: Stenotrophomonas maltophilia; SP: Scedosporium prolificans; BC: Burkholderia cepacia; SA: Staphylococcus aureus; NI: not identifiable; NA: not available.

Table 3.-Baseline sputum indices in cystic fibrosis (CF) patients compared to subjects with chronic obstructive pulmonary disease (COPD) and normal controls

Subjects n $\mathrm{TCC} \times 10^{6} \mathrm{~mL} \mathrm{~L}^{-1 \#} \quad$ Iron $\mu \mathrm{mol} \cdot \mathrm{L}^{-1 \uparrow} \quad$ Ferritin $\mathrm{mg} \cdot \mathrm{L}^{-1+}$ Albumin $\mathrm{dg} \cdot \mathrm{L}^{-1 \S} \mathrm{TNF}-\alpha \mu \mathrm{mol} \cdot \mathrm{L}^{-1 f} \mathrm{IL}-1 \beta \mu \mathrm{mol} \cdot \mathrm{L}^{-1 \# \#}$

\begin{tabular}{lrclllll}
\hline Acute CF & 19 & $39.5(3.4-255.0)$ & $44.4(17.0-128.7)$ & $3.6(1.5-9.5)$ & $0.7(0.1-3.9)$ & $7.3^{f}(2.4-45.0)$ & $22.5^{\# \#}(6.6-64.1)$ \\
Stable CF & 17 & $20.5(6.3-72.9)$ & $33.3(0-111.2)$ & $2.4(0.8-6.9)$ & $0.4(0.1-1.9)$ & $6.8(2.8-24.9)$ & $15.1(1.2-69.7)$ \\
Stable COPD & 8 & $0.9(0.2-3.2)$ & $15.5(0-66.6)$ & $0.6(0.1-1.0)$ & $0.2(0.1-0.3)$ & $3.3(0.8-6.2)$ & $0.2(0-1.5)$ \\
Normal controls & 6 & $0.4(0.3-1.7)$ & $0(0-13.2)$ & $0.2(0.004-0.3)$ & $0.1(0.002-0.6)$ & $2.3(0.7-6.3)$ & $0.5(0.2-1.0)$ \\
\hline
\end{tabular}

Data are presented as $\mathrm{n}$ and median (range). TCC: total cell counts; TNF: tumour necrosis factor; IL: interleukin. ${ }^{\#}$ : $\mathrm{p}<0.001 \mathrm{CF}$ (acute and stable) versus $C O P D$ and normal controls; ${ }^{\top}: p<0.001$ acute $C F$ versus normal controls, $p=0.02$ acute versus $C O P D, p=0.03$ stable $C F$ versus normal controls, $\mathrm{p}=0.1$ stable $\mathrm{CF}$ versus $\mathrm{COPD}{ }^{+}: \mathrm{p}<0.001 \mathrm{CF}$ (acute and stable) versus normal controls, $\mathrm{p}<0.001$ acute $\mathrm{CF}$ versus $\mathrm{COPD}, \mathrm{p}=0.01 \mathrm{stable} C \mathrm{CF}$ versus $\mathrm{COPD}, \mathrm{p}=0.04$ acute versus stable $\mathrm{CF} ;{ }^{\S}: \mathrm{p}<0.01 \mathrm{CF}$ (acute and stable) versus normal controls, $\mathrm{p}=0.04$ acute $\mathrm{CF}$ versus $\mathrm{COPD}, \mathrm{p}=0.02$ stable $\mathrm{CF}$ versus COPD; ${ }^{f}: \mathrm{p}<0.001 \mathrm{CF}$ (acute and stable) versus $\mathrm{COPD}, \mathrm{p}=0.003$ acute $\mathrm{CF}$ versus $\mathrm{COPD}, \mathrm{p}=0.001$ stable $\mathrm{CF}$ versus $\mathrm{COPD} ;{ }^{\# \#}: \mathrm{p}<0.01 \mathrm{CF}($ acute and stable) versus normal controls and COPD. 
Table 4.-Sputum results before (pre) and after (post) antimicrobial therapy

\begin{tabular}{lcc}
\hline & Good response & Poor response \\
\hline $\begin{array}{l}\text { Subjects } \\
\text { TCC } \times 10^{6} \cdot \mathrm{mL}^{-1}\end{array}$ & 14 & 5 \\
$\quad$ Pre & $40(3.4-255)$ & $39.0(7.6-51.5)$ \\
$\quad$ Post & $11.5(0.2-108)^{\#}$ & $63.4(27.6-83.6)$ \\
Iron $\mu \mathrm{mol} \cdot \mathrm{L}^{-1}$ & $47(18-129)$ & $27(20-46)$ \\
$\quad$ Pre & $33(0-90)^{+}$ & $46(30-80)$ \\
$\quad$ Post & $4.1(0.7-9.5)$ & $3.2(1.8-7.4)$ \\
Ferritin $\mathrm{mg} \cdot \mathrm{L}^{-1}$ & $2.3(0.3-8.5)^{-}$ & $3.5(2.8-5.8)$ \\
$\quad$ Pre & $0.7(0.1-3.0)$ & $0.5(0.4-1.4)$ \\
$\quad$ Post & $0.5(0.9-1.4)^{+}$ & $0.7(0.2-1.5)$ \\
Albumin $\mathrm{dg} \cdot \mathrm{L}^{-1}$ & & \\
$\quad$ Pre & $0.7(0.3-4.5)$ & $0.3(0.2-1.6)$ \\
$\quad$ Post & $0.5(0.3-2.1)^{+}$ & $0.6(0.2-0.7)$ \\
TNF- $\alpha \mu \mathrm{mol} \cdot \mathrm{L}^{-1}$ & & \\
$\quad$ Pre & & $13.1(6.7-29.6)$ \\
$\quad$ Post & $24.3(6.9-40.9)$ & $22.3(8.3-30.1)$ \\
$\quad$ Pre $1 \beta \mu \mathrm{mol} \cdot \mathrm{L}^{-1}$ & $10.4(1.4-28.9)^{\S}$ & \\
$\quad$ Post &
\end{tabular}

Data are presented as $\mathrm{n}$ and median (range) unless otherwise stated. A good response was defined as a reduction in fever, sputum volume and purulence and improvement in the general well-being of the patient. A poor response was defined as failure of the afore-mentioned indices to improve. Determining response to treatment was performed prospectively and was undertaken independently of knowledge of sputum indices. TCC: total cell counts; TNF: tumour necrosis factor; IL: interleukin. ${ }^{\#}: \mathrm{p}=0.03 ;{ }^{\uparrow}$ : $\mathrm{p}=0.001{ }^{+}: \mathrm{p}=0.1 ;{ }^{\S}: \mathrm{p}=0.009$; compared to baseline. reductions in sputum TCC $(\mathrm{p}=0.02)$ and iron $(\mathrm{p}=0.03)$, ferritin $(\mathrm{p}=0.001)$ and IL-1 $\beta$ levels $(\mathrm{p}=0.009)$, and weak trends toward reductions in TNF- $\alpha(\mathrm{p}=0.1)$ and albumin $(\mathrm{p}=0.1)$.

\section{Discussion}

In this study, it was demonstrated that CF sputum contains increased amounts of iron that correlate strongly with ferritin content and also to sputum concentrations of the ironregulatory cytokines, IL-1 $\beta$ and TNF- $\alpha$. Sputum microalbumin concentrations were similarly increased, suggesting that significant vascular leakage may be occurring as part of the inflammatory process in CF. Levels of sputum iron and ferritin in patients with stable CF were negatively correlated with disease severity. Antibiotic therapy during an acute exacerbation significantly reduced sputum TCC and levels of iron, ferritin and IL-1 $\beta$ in patients who were clinically improving, but not in patients who were deteriorating. Interestingly, patients with COPD had sputum iron levels that, although lower, were not significantly different to those of stable CF patients. This is consistent with the observation that tobacco smoke contains large amounts of iron, which probably contributes to smoking-related lung destruction [9]. The current findings suggest that an excess of iron within the lung may also be relevant to disease pathogenesis in $\mathrm{CF}$ and it is hypothesised that this may even facilitate $P$. aeruginosa infection. Finally, the response to antibiotic treatment suggests that determination of iron, ferritin and IL- $1 \beta$ concentrations in $\mathrm{CF}$ sputum may be useful as surrogate markers of disease

Table 5. - Correlations between inflammatory variables during an acute exacerbation of cystic fibrosis

\begin{tabular}{|c|c|c|c|c|c|c|}
\hline & $\mathrm{TCC}$ & $\mathrm{TNF}-\alpha$ & IL-1 $\beta$ & Iron & Ferritin & Albumin \\
\hline TCC & & $0.02(0.9)$ & $0.3(0.2)$ & $-0.06(0.8)$ & $0.8(<0.001)^{\#}$ & $0.8(<0.001)^{\#}$ \\
\hline TNF- $\alpha$ & $0.02(0.9)$ & & $0.2(0.4)$ & $0.7(0.001)^{\#}$ & $0.2(0.3)$ & $0.2(0.5)$ \\
\hline IL-1 $\beta$ & $0.3(0.2)$ & $0.2(0.4)$ & & $0.5(0.04)^{\#}$ & $0.5(0.06)$ & $0.4(0.09)$ \\
\hline Iron & $-0.06(0.8)$ & $0.7(0.001)^{\#}$ & $0.5(0.04)^{\#}$ & & $0.3(0.3)$ & $0.2(0.5)$ \\
\hline Ferritin & $0.8(<0.001)^{\#}$ & $0.2(0.3)$ & $0.5(0.06)$ & $0.3(0.3)$ & & $0.6(0.01)^{\#}$ \\
\hline Albumin & $0.8(<0.001)^{\#}$ & $0.2(0.5)$ & $0.4(0.09)$ & $0.2(0.5)$ & $0.6(0.01)^{\#}$ & \\
\hline
\end{tabular}

Data are presented as correlations (p-values). TCC: total cell counts; TNF: tumour necrosis factor; IL: interleukin. ${ }^{\#}$ : significant relationships.

Table 6. - Correlations between the relative changes $(\delta)$ in sputum variables with antibiotics

\begin{tabular}{|c|c|c|c|c|c|c|}
\hline & $\delta \mathrm{TCC}$ & $\delta \mathrm{TNF}-\alpha$ & $\delta$ IL-1 $\beta$ & $\delta$ Iron & $\delta$ Ferritin & $\delta$ Albumin \\
\hline$\delta$ TCC & & $0.07(0.8)$ & $0.3(0.3)$ & $0.08(0.7)$ & $0.4(0.08)$ & $0.2(0.4)$ \\
\hline$\delta \mathrm{TNF}-\alpha$ & $0.07(0.8)$ & & $0.3(0.2)$ & $0.7(0.001)^{\#}$ & $0.6(0.003)^{\#}$ & $0.8(<0.001)^{\#}$ \\
\hline$\delta$ IL-1 $\beta$ & $0.3(0.3)$ & $0.3(0.2)$ & & $0.5(0.07)$ & $0.6(0.01)^{\#}$ & $0.4(0.07)$ \\
\hline$\delta$ Iron & $0.08(0.7)$ & $0.7(0.001)^{\#}$ & $0.3(0.2)$ & & $0.5(0.04)^{\#}$ & $0.6(0.01)^{\#}$ \\
\hline$\delta$ Ferritin & $0.4(0.08)$ & $0.6(0.003)^{\#}$ & $0.6(0.01)^{\#}$ & $0.5(0.04)^{\#}$ & & $0.8(<0.001)^{\#}$ \\
\hline$\delta$ Albumin & $0.2(0.4)$ & $0.8(<0.001)^{\#}$ & $0.4(0.07)$ & $0.6(0.01)^{\#}$ & $0.8(<0.001)^{\#}$ & \\
\hline
\end{tabular}

Data are presented as correlations (p-values). TCC: total cell counts; TNF: tumour necrosis factor; IL: interleukin. ${ }^{\#}$ : significant relationships.

Table 7.-Correlations between inflammatory variables in stable cystic fibrosis patients

\begin{tabular}{|c|c|c|c|c|c|c|}
\hline & $\mathrm{TCC}$ & $\mathrm{TNF}-\alpha$ & IL-1 $\beta$ & Iron & Ferritin & Albumin \\
\hline TCC & & $0.5(0.07)$ & $0.5(0.02)^{\#}$ & $-0.06(0.8)$ & $0.3(0.3)$ & $0.1(0.6)$ \\
\hline TNF- $\alpha$ & $0.5(0.07)$ & & $0.7(0.002)^{\#}$ & $0.6(0.009)^{\#}$ & $0.6(0.01)^{\#}$ & $0.3(0.2)$ \\
\hline IL-1 $\beta$ & $0.5(0.02)^{\#}$ & $0.7(0.002)^{\#}$ & & $0.7(0.001)^{\#}$ & $0.8(<0.001)^{\#}$ & $0.7(0.002)^{\#}$ \\
\hline Iron & $0.5(0.05)^{\#}$ & $0.6(0.009)^{\#}$ & $0.7(0.001)^{\#}$ & & $0.8(<0.001)^{\#}$ & $0.7(0.003)^{\#}$ \\
\hline Ferritin & $0.3(0.3)$ & $0.6(0.01)^{\#}$ & $0.8(<0.001)^{\#}$ & $0.8(<0.001)^{\#}$ & & $0.6(0.01)^{\#}$ \\
\hline Albumin & $0.1(0.6)$ & $0.3(0.2)$ & $0.7(0.002)^{\#}$ & $0.7(0.003)^{\#}$ & $0.6(0.01)^{\#}$ & \\
\hline
\end{tabular}

Data are presented as correlations (p-values). TCC: total cell counts; TNF: tumour necrosis factor; IL: interleukin. ${ }^{\#}$ : significant relationships. 
activity that could be followed to guide therapy and, potentially, as warning of impending deterioration.

$P$. aeruginosa is regularly identifiable within the sputum of most CF patients by 6 yrs of age, although why this organism preferentially colonises the lung in this disease remains unknown [1]. However, once $P$. aeruginosa appears within the airways, it signifies progressive deterioration and lung destruction. Availability of iron is critical to $P$. aeruginosa and it is highly effective at obtaining ferric iron from its environment by secreting high-affinity iron-sequestering siderophores, which cleave iron from host binding molecules such as ferritin [10-13]. The CF lung has previously been considered to be an iron-deplete environment, although more recent data suggest that this may not be the case [14, 15]. The current authors have extended these observations and demonstrated a novel relationship between sputum iron content and levels of IL-1 $\beta$ and TNF- $\alpha$ in vivo, cytokines that are thought to have an iron-regulatory function via modulation of ferritin synthesis [16-18]. Consistent with this role, the current authors have demonstrated that changes in these cytokines with treatment are strongly related to changes in ferritin levels.

Airway epithelial cells and macrophages are probably the predominant source of the IL- $1 \beta$ and TNF- $\alpha$ detected in this study [18, 19]. Up-regulation of these cytokines occurs in response to exposure to the lipopolysaccharide of Gramnegative micro-organisms such as $P$. aeruginosa, although the presence of iron and neutrophil pro-oxidants within the airway may themselves promote their expression. The current finding of greatly increased concentrations of ferritin probably reflects release of intracellular stores as a consequence of inflammatory and epithelial cell death or apoptosis [19]. Although ferritin is normally thought to constitute an important defence mechanism that denies $P$. aeruginosa access to iron and prevents generation of toxic hydroxyl radicals, under certain circumstances it may, in fact, facilitate these processes [4, 20]. Indeed, extracellular ferritin readily releases its core of ferric $\left(\mathrm{Fe}^{3+}\right)$ iron in the presence of $P$. aeruginosa siderophores and, further, superoxide anions produced by activated polymorphonuclear cells (PMN) allow "free" iron to catalyse the formation of damaging hydroxyl radicals [21-23].

Treatment of acute exacerbations of $\mathrm{CF}$ is primarily aimed at suppressing $P$. aeruginosa infection by chemo- and physical therapy, thereby reducing the host inflammatory response that is ineffective and harmful [24]. The current authors' findings of very high levels of iron and ferritin within the airways during an acute exacerbation suggest that the $\mathrm{CF}$ lung may provide a particularly favourable environment for $P$. aeruginosa, and may partly explain why accelerated $P$. aeruginosa replication cannot be compensated for by increased PMN phagocytosis. Indeed, increased iron may actually interfere with PMN phagocytosis and macrophage function directly, further compromising host defences [25-28]. In a number of the studied patients who responded poorly to antibiotics, sputum TCC and mediator levels remained essentially unchanged or even rose, suggesting the potential existence of a refractory burden of infection and increased intensity of airway inflammation in these individuals. Unfortunately, the current authors did not perform quantitative bacterial counts to allow further comment, but a reduction in $P$. aeruginosa load remains the most likely explanation for the significant reductions in sputum iron, ferritin and IL-1 $\beta$ seen following antibiotic therapy. Few studies have, in fact, assessed the magnitude of the host inflammatory response in relation to bacterial load in CF. Quantitative determination of $P$. aeruginosa load was not routinely available at the current authors' institution (Alfred Hospital, Melbourne, Australia) at the time that this analysis was undertaken, but the current authors would argue that future comments on the host inflammatory response should only be made with accurate knowledge of the burden of infection.

Whatever the precise aetiology, the high levels of iron and ferritin in the current study, even during the stable state, and their relationship to disease severity, as well as the observation that reductions in their levels mirrored beneficial clinical response to antimicrobial therapy, suggests that measuring their concentrations in sputum may be of clinical and prognostic use. Failure to reduce levels adequately may indicate the need to change treatment and, similarly, increases may suggest an impending deterioration. The relationship between sputum ferritin and TCC in the acute patients suggests an association with acute cellular inflammation, but it is important to note that iron was poorly related to sputum total cells in CF patients, irrespective of clinical status. This implies to the current authors that the increased iron and ferritin detected is not simply an inflammatory epiphenomenon, but that other explanations need to be considered, such as active acquisition of iron by bacterial siderophores from host tissues. To the current authors' knowledge, a direct causal relationship between the iron content of the $\mathrm{CF}$ airway and $P$. aeruginosa infection has not been previously proposed, but this is such an important prospect that it should stimulate further investigations. Particular focus should perhaps be on $\mathrm{CF}$ infants who are not yet infected with $P$. aeruginosa to determine whether iron or iron-related mediators are detectable within the airway at this very early stage of disease. The potential relevance of iron homeostasis within the CF lung is further highlighted by the observation that lactoferrin, a component of the innate immune system, can prevent biofilm formation by $P$. aeruginosa via inhibition of iron-induced "twitching motility" [29].

Finally, although the relationship between sputum microalbumin concentrations and iron and ferritin content may suggest that vascular leakage is contributing to iron and ferritin within the airway, the current authors believe that this is unlikely because the sputum levels of iron and ferritin exceeded those of normal serum. Additionally, occult haemorrhage could not account for the high levels of ferritin detected, as erythrocytes contain almost negligible amounts of ferritin $\left(<10^{-19} \mathrm{~g} \cdot \mathrm{L}^{-1}\right)$ and patients who had no history of recent haemorrhage or even blood streaking were deliberately chosen $[30,31]$

In conclusion, the current authors have demonstrated that the cystic fibrosis airway contains large amounts of iron and ferritin during acute exacerbations and also in stable disease. Similarly, both interleukin- $1 \beta$ and tumour necrosis factor- $\alpha$ are detectable in sputum in increased concentrations and the current findings suggest both of these cytokines may be involved in airway iron homeostasis in cystic fibrosis. Whether the observed increase in airway iron is simply related to airway inflammation or reflects active acquisition by Pseudomonas aeruginosa, or possibly even a constitutive iron-handling problem in cystic fibrosis, needs to be urgently determined. Better understanding of iron homeostasis in the airway in cystic fibrosis could lead to important therapeutic innovations.

Acknowledgements. The authors would like to thank J.W. Wilson and T.C. Kotsimbos for allowing some of their patients to participate.

\section{References}

1. Hoiby N. Cystic fibrosis: infection. Schweiz Med Wochenschr 1991; 121: 105-109.

2. Romling U, Fiedler B, Bosshammer J, et al. Epidemiology of 
chronic Pseudomonas aeruginosa infections in cystic fibrosis. J Infect Dis 1994; 170: 1616-1621.

3. Schuster A, Haarmann A, Wahn V. Cytokines in neutrophildominated airway inflammation in patients with cystic fibrosis. Eur Arch Otorhinolaryngol 1995; 252: Suppl. 1, S59-S60.

4. Mateos F, Brock JH, Perez-Arellano JL. Iron metabolism in the lower respiratory tract. Thorax 1998; 53: 594-600.

5. Reid DW, Withers NJ, Francis L, Wilson JW, Kotsimbos TC. Iron deficiency in cystic fibrosis: relationship to lung disease severity and chronic Pseudomonas aeruginosa infection. Chest 2002; 121: 48-54.

6. Kochanowski BA, Sherman AR. Cellular growth in irondeficient rat pups. Growth 1982; 46: 126-134.

7. Pizzichini E, Pizzichini MM, Efthimiadis A, Hargreave FE, Dolovich J. Measurement of inflammatory indices in induced sputum: effects of selection of sputum to minimize salivary contamination. Eur Respir J 1996; 9: 1174-1180.

8. Bland JM, Altman DG. A note on the use of the intraclass correlation coefficient in the evaluation of agreement between two methods of measurement. Comput Biol Med 1990; 20: 337-340.

9. Nelson ME, O'Brien-Ladner AR, Wesselius LJ. Regional variation in iron and iron-binding proteins within the lungs of smokers. Am J Respir Crit Care Med 1996; 153: 1353-1358.

10. van Asbeck BS, Verhoef J. Iron and host defence. Eur J Clin Microbiol 1983; 2: 6-10.

11. Bullen JJ, Ward CG, Wallis SN. Virulence and the role of iron in Pseudomonas aeruginosa infection. Infect Immun 1974; 10: 443-450.

12. Haas B, Kraut J, Marks J, Zanker SC, Castignetti D. Siderophore presence in sputa of cystic fibrosis patients. Infect Immun 1991; 59: 3997-4000.

13. Haas B, Murphy E, Castignetti D. Siderophore synthesis by mucoid Pseudomonas aeruginosa strains isolated from cystic fibrosis patients. Can J Microbiol 1991; 37: 654-657.

14. Stites SW, Plautz MW, Bailey K, O'Brien-Ladner AR, Wesselius LJ. Increased concentrations of iron and isoferritins in the lower respiratory tract of patients with stable cystic fibrosis. Am J Respir Crit Care Med 1999; 160: 796801.

15. Stites SW, Walters B, O'Brien-Ladner AR, Bailey K, Wesselius LJ. Increased iron and ferritin content of sputum from patients with cystic fibrosis or chronic bronchitis. Chest 1998; 114: 814-819.

16. Wei Y, Miller SC, Tsuji Y, Torti SV, Torti FM. Interleukin 1 induces ferritin heavy chain in human muscle cells. Biochem Biophys Res Commun 1990; 169: 289-296.

17. Tsuji Y, Miller LL, Miller SC, Torti SV, Torti FM. Tumor necrosis factor-alpha and interleukin 1-alpha regulate transferrin receptor in human diploid fibroblasts. Relationship to the induction of ferritin heavy chain. J Biol Chem 1991; 266: 7257-7261.

18. O'Brien-Ladner AR, Blumer BM, Wesselius LJ. Differential regulation of human alveolar macrophage-derived interleukin-1beta and tumor necrosis factor-alpha by iron. J Lab Clin Med 1998; 132: 497-506.

19. Saavedra M, Vasil M, Randell S, West J, Rodman D. Pseudomonas aeruginosa-human airway epithelial cell interaction: effects of iron on inflammation and apoptosis. Chest 2002; 121: Suppl. 3, 40S-41S

20. Reif DW. Ferritin as a source of iron for oxidative damage Free Radic Biol Med 1992; 12: 417-427.

21. Britigan BE, Hayek MB, Doebbeling BN, Fick Jr RB. Transferrin and lactoferrin undergo proteolytic cleavage in the Pseudomonas aeruginosa-infected lungs of patients with cystic fibrosis. Infect Immun 1993; 61: 5049-5055.

22. Biemond P, Swaak AJ, Beindorff CM, Koster JF. Superoxidedependent and -independent mechanisms of iron mobilization from ferritin by xanthine oxidase. Implications for oxygen-free-radical-induced tissue destruction during ischaemia and inflammation. Biochem $J$ 1986; 239: 169-173.

23. Biemond P, Swaak AJ, van Eijk HG, Koster JF. Superoxide dependent iron release from ferritin in inflammatory diseases. Free Radic Biol Med 1988; 4: 185-198.

24. Jaffar-Bandjee MC, Lazdunski A, Bally M, Carrere J, Chazalette JP, Galabert C. Production of elastase, exotoxin $\mathrm{A}$, and alkaline protease in sputa during pulmonary exacerbation of cystic fibrosis in patients chronically infected by Pseudomonas aeruginosa. J Clin Microbiol 1995; 33: 924-929.

25. Wiener E. Impaired phagocyte antibacterial effector functions in beta-thalassemia: a likely factor in the increased susceptibility to bacterial infections. Hematology 2003; 8: 35-40.

26. Hor LI, Chang YK, Chang CC, Lei HY, Ou JT. Mechanism of high susceptibility of iron-overloaded mouse to Vibrio vulnificus infection. Microbiol Immunol 2000; 44: 871-878.

27. Farmakis D, Giakoumis A, Aessopos A, Polymeropoulos E. Pathogenetic aspects of immune deficiency associated with beta-thalassemia. Med Sci Monit 2003; 9: 19-22.

28. van Asbeck BS, Marx JJ, Struyvenberg A, van Kats JH, Verhoef J. Effect of iron (III) in the presence of various ligands on the phagocytic and metabolic activity of human polymorphonuclear leukocytes. J Immunol 1984; 132: 851856

29. Singh PK, Parsek MR, Greenberg EP, Welsh AJ. A component of innate immunity prevents bacterial biofilm development. Nature 2002; 417: 552-555.

30. Mae H. The relationship between RBC ferritin content in chronic liver diseases and iron deposition in hepatocytes. Hokkaido Igaku Zasshi 1994; 69: 1244-1251.

31. Guillemin C, Plomteux G, Dezier JF, et al. Reference values of erythrocyte ferritin in children and adults. Ann Biol Clin (Paris) 1989; 47: 203-206. 